Article

\title{
Properties of Extrusion Concrete Panel Using Waste Concrete Powder
}

\author{
Ha-Seog Kim ${ }^{1}$, Sea-Hyun Lee ${ }^{2}$ and Byoungil Kim ${ }^{3, *}$ \\ 1 Department of Architectural Engineering, Kongju National University, 275 Cheonan-daero, Cheonan City, \\ Chungcheongnam-do 330-717, Korea; bravo3po@kongju.ac.kr \\ 2 Building and Urban Research Institute, Korea Institute of Civil Engineering and Building Technology, \\ Ilsanseo-gu, Goyang 411-712, Korea; shlee@kict.re.kr \\ 3 School of Architecture, Seoul National University of Science \& Technology, 232 Gongneung-ro, Nowon-gu, \\ Seoul 01811, Korea \\ * Correspondence: bikim@seoultech.ac.kr; Tel.: +82-2-970-6512
}

Received: 30 July 2017; Accepted: 31 August 2017; Published: 5 September 2017

\begin{abstract}
There has been an increasing amount of waste concrete generated in recent years, which has made recycling more important. Waste concrete is generally recycled as recycled aggregates, and many studies have been conducted to seek ways to improve their quality. Such quality improvement processes has led to the generation of byproducts such as waste concrete powder, which needs to be recycled efficiently based on further research. Accordingly, this study was conducted with the aim to use waste concrete powder (WCP) to substitute silica powder in the manufacturing of the extrusion concrete panels in cases where high $\mathrm{SiO}_{2}$ content is not a requirement. The results of this study showed a negative correlation between flexural strength and silica powder-WCP substitution ratio. For example, 50\% substitution resulted in a product that satisfied the required flexural strength over $14 \mathrm{MPa}$ as stipulated by the Korean Industrials Standards, and it gave rise to properties such as specific gravity, absorption ratio, length change, thermal conductivity, and fire-resistance that were similar to those of plain specimens. Based on these results, it was deemed that it would be possible to use WCP as an alternative material in place of siliceous fillers in cases where high-purity is not required.
\end{abstract}

Keywords: waste concrete; waste concrete powder; extrusion panel; concrete panel; recycling; silica powder

\section{Introduction}

Concrete is a material that is used widely across human society, as it is a major component of various social infrastructures such as buildings, roads, and bridges. Given their widespread use, massive amounts of waste concrete are generated during the deconstruction and demolition of such structures. Concrete is mostly comprised of aggregates in terms of volume, and various environmental issues arise from collecting aggregates from rivers and land. For this reason, annual aggregate supply plans are established at the state level in Korea as a means to limit the acquisition of natural aggregates, and it is recommended that industrial byproducts such as waste concrete and steel slags be used to obtain aggregate instead [1].

Recycled aggregates obtained by crus hing and grinding waste concrete have higher absorption rates and a lower strength in comparison to natural aggregates. For this reason, concrete made with recycled aggregates naturally has substandard properties. In order to mitigate these issues, research has been performed to enhance the quality of recycled aggregates. The quality improvement processes can largely be divided into the wet type and the dry type. The wet processes involve the elution of calcium hydroxide, comprising of cement paste, for the purpose of weakening its strength and increasing 
the difference of strength between the natural aggregates included in waste concrete and the cement paste as a means to enhance the separation efficiency. On the other hand, in the dry processes, an impact-type grinder is used to enhance the grinding efficiency, and the separation efficiency is determined based on the performance level of the grinder. In both processes, the amount of byproducts produced inevitably increases in relation to the enhanced quality of the recycled aggregates recovered. In the case of waste concrete powder (WCP), which is one of the byproducts of these processes, it is typically buried into the ground with soil as there are no suitable areas for its use, and thus, the issue of treating and recycling WCP has grown increasingly important. However, the byproducts arising from the wet processes are in the form of slurry, which means that they must be dehydrated and dried before they can be recycled, whereas the byproducts from the dry processes are relatively easier to recycle in comparison [2].

As for the concrete extrusion panel, it is a product manufactured through the continuous process of extrusion by using silica powder and pulp fiber as the main constituents and cement as a binder, and it is steam and autoclave cured after formation. Autoclave curing is performed for the purpose of improving the strength of the specimen by forming tobermorite, which is a calcium silicate hydrate. In these cases, silica powder acts as a source of $\mathrm{SiO}_{2}$, as well as filler for the pores. Generally speaking, silica powder is added in more than a sufficient amount necessary for the reaction, and thus, low-grade silica powder, with less than $97 \% \mathrm{SiO}_{2}$ content, is used to reduce costs [3].

A review of the trends in research performed on such concrete extrusion panels showed that Kim et al. $(2006,2012)$ employed stone powder sludge as a means to improve the cost-effectiveness of panel production, while Choi et al. (2013) used alpha-hemihydrate gypsum to improve the fire-resistance of the panels. In the case of substituting silica powder with stone powder sludge, there was an increase in the absorption rate and a decrease in the density and flexural strength with higher substitution ratios, based on which it was deemed important to maintain an appropriate mixing ratio. In the case of substituting cement with alpha-hemihydrate gypsum, it was shown to improve the fire-resistance and slightly enhance the sound insulation, while maintaining the strength and dimensional stability of the concrete extrusion panel. The purpose of this type of research has been to maintain the existing performance levels, or to enhance some of the performances of panels, while reducing the cost of production by using recycled materials [4-6].

As a part of these efforts, this study aimed to apply WCP to the concrete extrusion panel production. The byproducts arising from the dry processes of recycled aggregate production are fine particles as they are typically generated in the crushing process, and they contain silica as the waste concrete, from which they are derived, contain sand and pebbles [7-9]. Based on this, it was deemed that such byproducts could replace the silica powder, acting as a filler and silica source, so that the use of natural resources and panel production costs could be reduced.

\section{Materials and Methods}

\subsection{Experimental Plan}

This study was conducted with the aim to examine the variations in the characteristics of the extrusion concrete panels according to the amount of silica powder, used as aggregates, substituted with WCP. The experimental plan is shown in Table 1. The experimental factor was determined to be the silica powder-WCP substitution ratio, and extrusion of the specimen was performed at substitution ratios of $0,25,50,75$, and $100 \mathrm{wt} \%$. Then, the characteristics of extraction concrete panel specimens specified by the Korean Industrial Standards (KS), such as flexural strength, specific gravity, absorption rate, rate of change in length, and thermal conductivity according to absorption, and fire-resistance were reviewed. 
Table 1. Experimental plan.

\begin{tabular}{ccc}
\hline Factors & Levels & Test Items \\
\hline \multirow{2}{*}{ Aggregate } & Silica powder WCP & Flexural strength \\
& & Specific density \\
& Absorption ratio \\
& & Length change \\
Replacement ratio $(\mathrm{wt} \%)$ & $0,25,50,75,100$ & Thermal conductivity \\
& & Fire-resistance \\
\hline
\end{tabular}

* WCP: Waste concrete powder.

\subsection{Materials}

As for the cement, ordinary Portland cement (OPC) (Table 2) as prescribed in KS L 5201 was used. As a source of $\mathrm{SiO}_{2}$, silica powder plays an important role in the production of tobermorite in the process of autoclave curing, and also fills the voids of a cement matrix during extrusion.

Table 2. Physical and chemical properties of ordinary Portland cement (OPC).

\begin{tabular}{|c|c|c|c|c|c|c|c|}
\hline \multirow{2}{*}{\multicolumn{2}{|c|}{ Density $\left(\mathrm{g} / \mathrm{cm}^{3}\right)$}} & \multirow{2}{*}{ Blaine $\left(\mathrm{cm}^{2} / \mathrm{g}\right)$} & \multicolumn{5}{|c|}{ Setting Time } \\
\hline & & & \multicolumn{2}{|r|}{ Start (min) } & \multicolumn{3}{|c|}{ Finish (min) } \\
\hline \multicolumn{2}{|c|}{3.15} & 3240 & & 290 & & 380 & \\
\hline \multicolumn{8}{|c|}{ Chemical composition (\%) } \\
\hline LOI & $\mathrm{SiO}_{2}$ & $\mathrm{Al}_{2} \mathrm{O}_{3}$ & $\mathrm{Fe}_{2} \mathrm{O}_{3}$ & $\mathrm{CaO}$ & $\mathrm{MgO}$ & $\mathrm{SO}_{3}$ & $\mathrm{~K}_{2} \mathrm{O}$ \\
\hline 0.35 & 21.88 & 5.02 & 3.66 & 64.18 & 2.01 & 1.83 & 0.92 \\
\hline
\end{tabular}

In this experiment, silica powder produced in Korea with the lowest grade of $\mathrm{SiO}_{2}$ purity $<97 \%$ and 4000 Blaine $\left(\mathrm{cm}^{3} / \mathrm{g}\right)$ was used. As for the reinforcement fiber, sepiolite fiber and pulp fiber were used, and these reinforce the strength by smoothing the product surface during extrusion as they have a high water absorption rate. A viscosity agent is used as a means to promote the fluidity of a mix paste, and the dosage was $0.7 \%$ of the paste weight ratio. During extrusion, high shear stress is applied as the mix paste becomes compressed and consolidated by the auger screw present inside of the extruder. For this reason, the fluidity and consistency of the mix paste are highly important, and without a viscosity agent, the unit water content needs to be extremely high and it becomes difficult to maintain the shape of the formed product [10]. The commonly used viscosity agents include hydroxypropyl methylcellulose, hydroxyethyl methylcellulose, and ethyl hydroxyl cellulose. In this particular experiment, hydroxyl ethyl methyl cellulose was used. Wollastonite is used in the extrusion concrete panel production for the purpose of improving the fire-resistance in place of asbestos, the use of which is restricted in construction as it is known to be harmful to humans due to the fact that it is a mineral synthesized by the supply of silicate with the penetration of magma into carbonate rock, and it has a high melting point of $1540{ }^{\circ} \mathrm{C}$.

\subsection{Waste Concrete Powder}

The waste concrete powder that was used was generated by Korean company D, which manufactures recycled aggregates by using dry-type processes. The general process and mass balance are shown in Figure 1. In this process, carried out to produce recycled aggregates that are below $5 \mathrm{~mm}$ in size, waste concrete is first inputted into a roller crusher for the primary crushing process, and the impurities are filtered out through the screening process. The waste concrete materials that are below $5 \mathrm{~mm}$ in size are then fed into the 1-1 and 1-2 separators for aggregate production, while those that are above $5 \mathrm{~mm}$ in size are fed into a vertical shaft impact crusher (VSIC) so that they can be crushed further to be below $5 \mathrm{~mm}$ in size before being fed into the 2-1 and 2-2 separators for aggregate 
production. Powder generated from each of the separators is collected by the dust collector, and it should be noted that $23.7 \%$ of the inputted waste concrete was turned into WCP in this experiment.

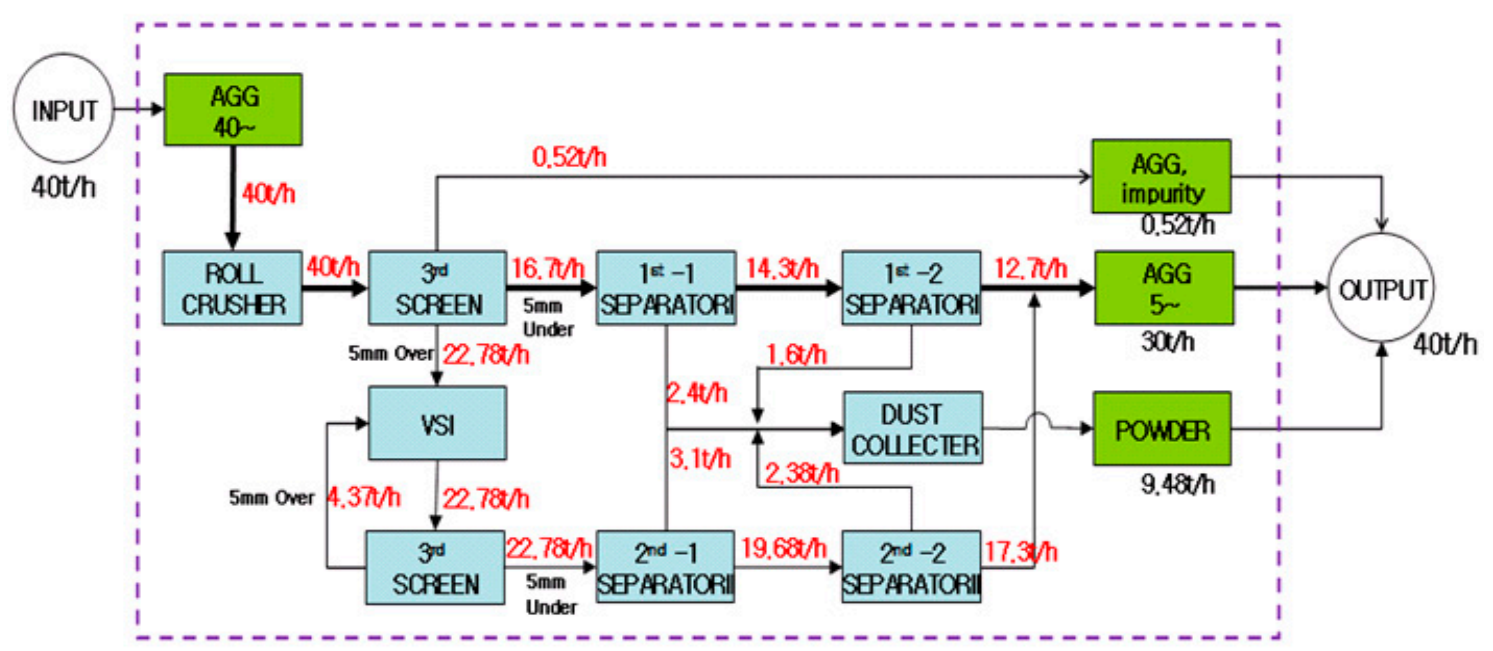

Figure 1. Flow and mass balance of waste concrete recycling process.

Figure 2 shows that the intermediate particle size (ave. $65 \mu \mathrm{m}$ ) of WCP collected by the dust collector was 44 , while the maximum particle size was over a hundred $\mu \mathrm{m}$. Table 3 shows the results of analyzing the composition of the silica powder and WCP used in this experiment. The silica powder had a $95 \% \mathrm{SiO}_{2}$ content, whereas $\mathrm{WCP}$ had $30 \% \mathrm{SiO}_{2}$ and $\mathrm{CaO}$ contents. Figure 3 shows that WCP particles from SEM are largely the harsh surface structure including the long-flat-slender types of features (left), as well as the existence of ettringite and calcium hydroxide $\left(\mathrm{Ca}(\mathrm{OH})_{2}\right)$, which are the hydration reaction products (right). A ball mill was used to grind WCP to have a similar fineness as the silica powder (approx. $4000 \mathrm{~cm}^{2} / \mathrm{g}$ ), and the grinding conditions and the resulting fineness are shown in Figure 4.

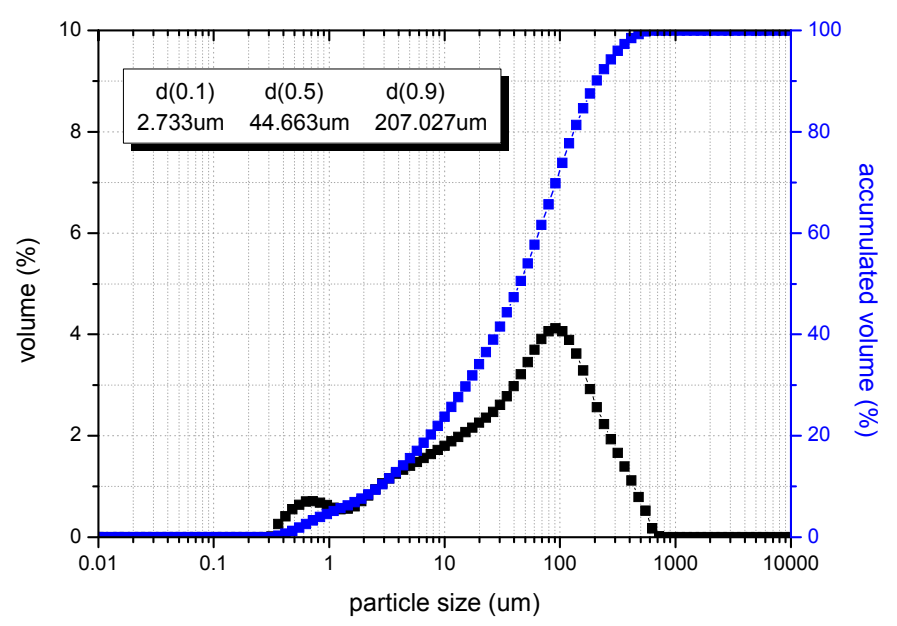

Figure 2. Particle size analysis of waste concrete powder (WCP).

Table 3. Properties of waste concrete powder (WCP) and silica powder.

\begin{tabular}{|c|c|c|c|c|c|c|c|c|c|}
\hline \multicolumn{8}{|c|}{ Chemical Composition (wt \%) } & \multirow{2}{*}{$\begin{array}{l}\text { Density } \\
\left(\mathrm{g} / \mathrm{cm}^{3}\right)\end{array}$} & \multirow{2}{*}{$\begin{array}{l}\text { Blaine } \\
\left(\mathrm{cm}^{2} / \mathrm{g}\right)\end{array}$} \\
\hline & LOI & $\mathrm{SiO}_{2}$ & $\mathrm{CaO}$ & $\mathrm{Fe}_{2} \mathrm{O}_{3}$ & $\mathrm{Al}_{2} \mathrm{O}_{3}$ & $\mathrm{~K}_{2} \mathrm{O}$ & $\mathrm{SO}_{3}$ & & \\
\hline WCP & 2.8 & 31.8 & 39.0 & 10.5 & 7.4 & 4.7 & 3.5 & 2.60 & $<1000$ \\
\hline Silica powder & 1.7 & 95.5 & - & 0.7 & 1.9 & - & - & 2.66 & 4160 \\
\hline
\end{tabular}




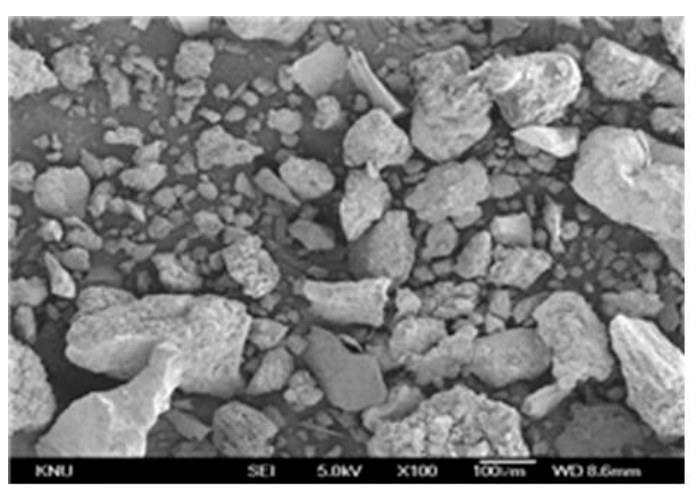

Magnification $(\times 100)$

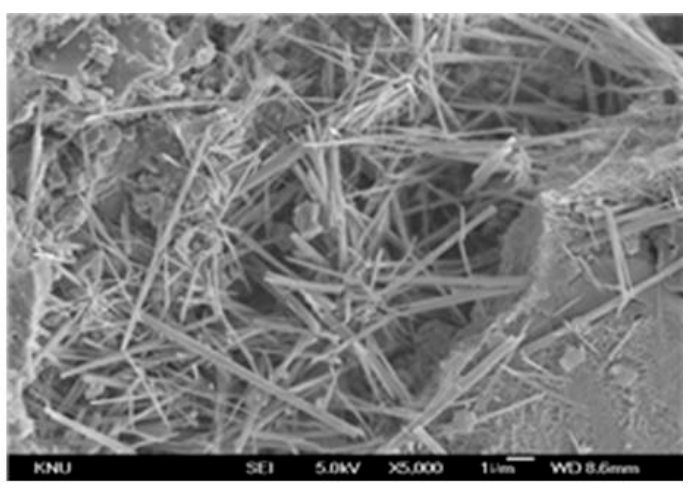

Magnification $(\times 5000)$

Figure 3. Waste concrete powder SEM images.

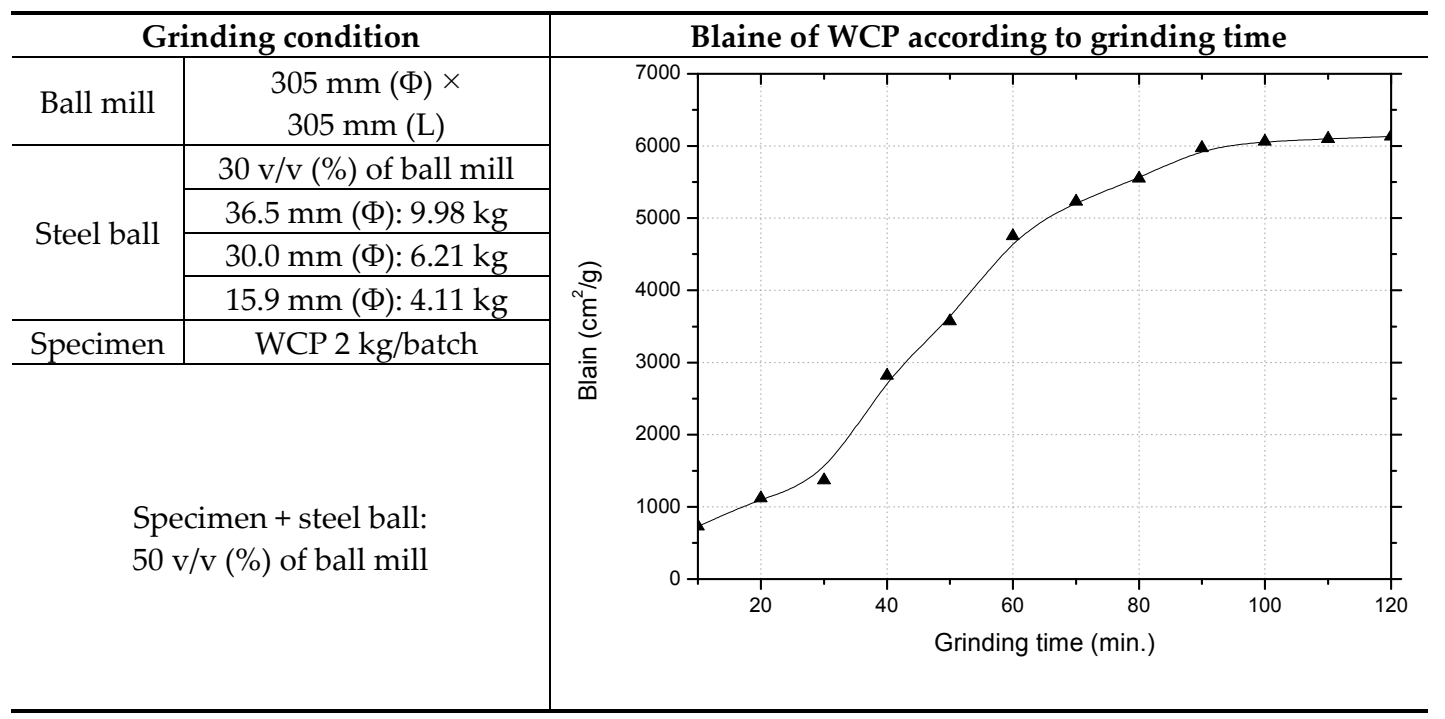

Figure 4. Blaine change according to grinding of WCP.

\subsection{Experiment Method}

The extrusion was performed using the extruder model SY-05S, manufactured by Japanese company I to form a panel with a $50 \times 50 \mathrm{~mm}$ dimension. The panels were extruded by wet mixing (5 min) with a kneader mixer right after dry mixing ( $3 \mathrm{~min}$ ) with the binder-fiber materials. Then, it was cut at every $200 \mathrm{~mm}$ in length to fabricate the specimens for the strength assessment. The experimental method is described in detail in Figure 5. Experimental products were then produced by applying the mixing ratio that would satisfy the strength specification prescribed in KS F 4735, and an assessment was carried out in regard to the strength, thermal conductivity, specific gravity, absorption rate, rate of change in length caused by water absorption, and fire-resistance [11,12]. 


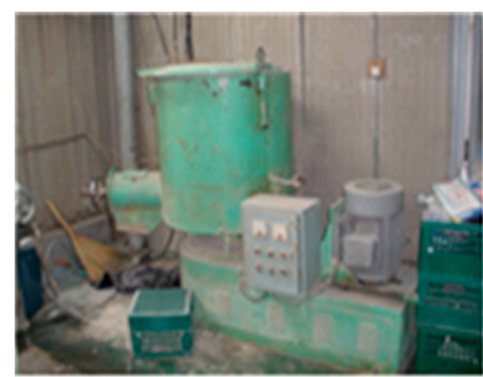

Dry mixing

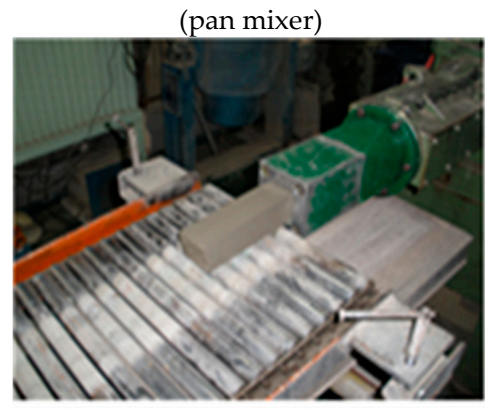

Extruding

$(50 \times 50 \mathrm{~mm})$

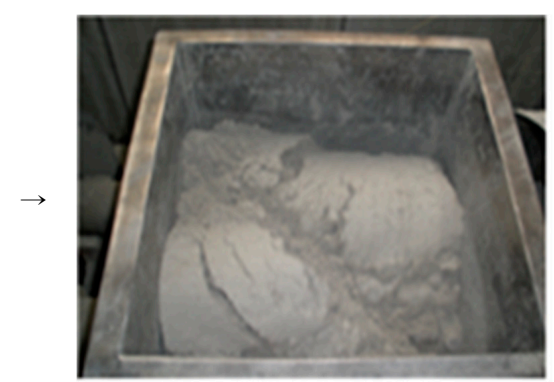

Wet mixing

(kneader mixer)

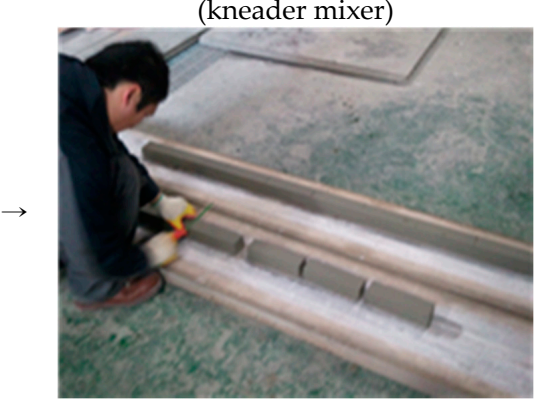

Cutting

$(50 \times 50 \times 200 \mathrm{~mm})$

Figure 5. Experimental method.

\subsection{Curing Method}

The early-age strength and dimensional stability of an extrusion panel, a secondary concrete product, are important factors. For this reason, autoclave curing is performed to rapidly stabilize the structure and to achieve a degree of strength that is above a certain level. Figure 6 shows the curing method that is employed in this experiment. Steam curing was performed first on the panel extruded in air at $80^{\circ} \mathrm{C}$ and normal pressure, and autoclave curing was performed at $180^{\circ} \mathrm{C}, 10 \mathrm{~atm}$. Majority of $\mathrm{CaO}-\mathrm{SiO}_{2}-\mathrm{H}_{2} \mathrm{O}(\mathrm{C}-\mathrm{S}-\mathrm{H})$ hydrates are insoluble, and hydrates produced at temperatures below $100{ }^{\circ} \mathrm{C}$ are instable crystal structures. This is the case for CSH (I) and CSH (II), which are produced as a result of cement hydration. However, $\mathrm{CSH}$, which underwent hydrothermal synthesis by autoclave curing at temperatures above $100{ }^{\circ} \mathrm{C}$, is a relatively stable crystal structure that can be used as a hardened calcium silicate. Figure 7 shows the compounds of the C-S-H system. The autoclave curing process was performed for the purpose of synthesizing $11 \AA$ tobermorite $\left(\mathrm{C}_{5} \mathrm{~S}_{6} \mathrm{H}_{5}\right)$ and $14 \AA$ tobermorite $\left(\mathrm{C}_{5} \mathrm{~S}_{6} \mathrm{H}_{9}\right)$, found at the center of the diagram [13-15].

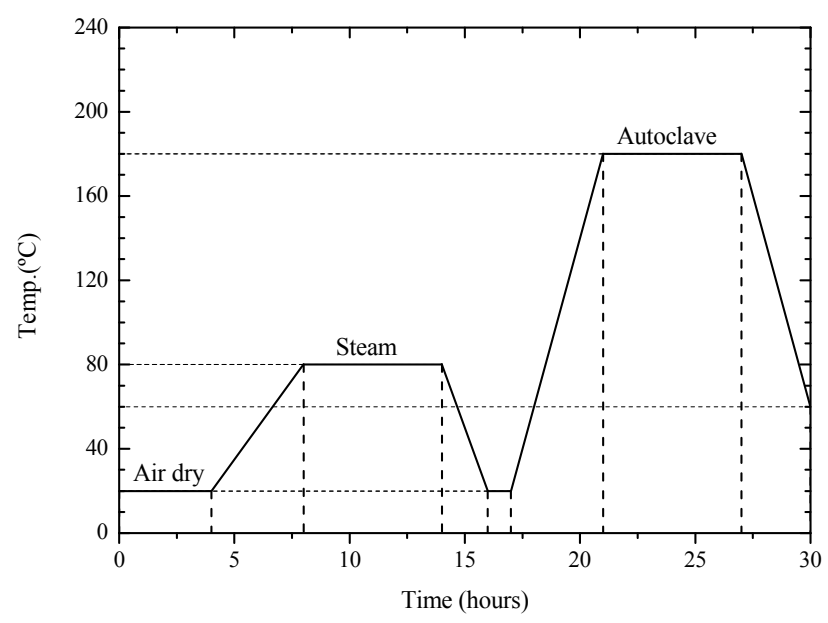

Figure 6. Curing process. 


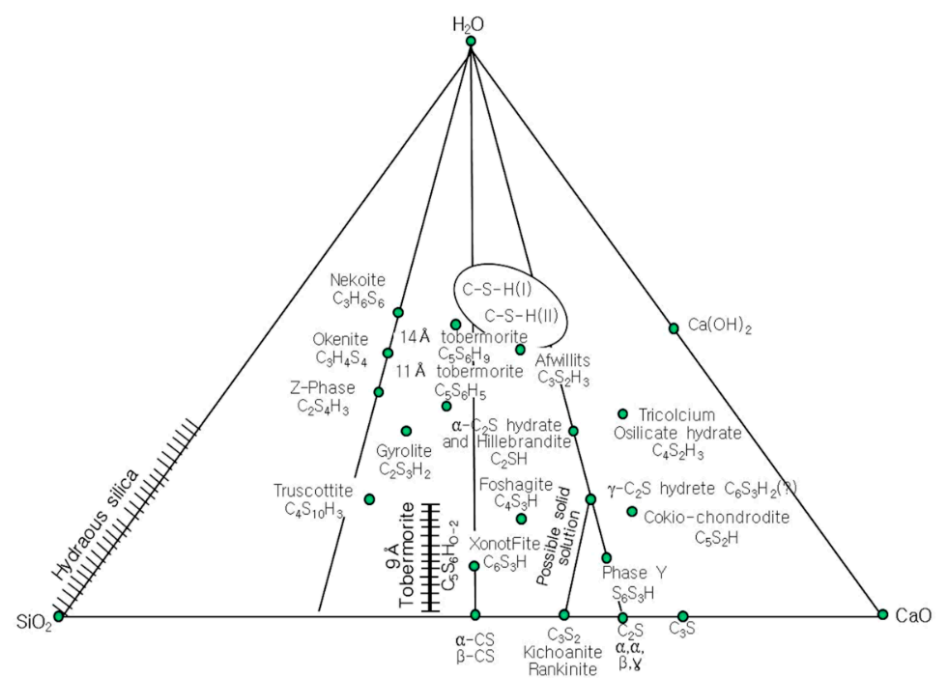

Figure 7. Compounds in C-S-H system.

\section{Results}

\subsection{Strength}

As described above, a bar-type extrusion experiment was carried out prior to the panel formation in order to examine whether the mix using WCP resulted in a strength level that satisfied the prescribed level for extrusion concrete panels. Table 4 shows the mix for the specimen production, and the number in the ID signifies the silica powder-WCP substitution ratio in terms of weight. The results of measuring the strength for the averaged 3 specimens for each mixing are shown in Figure 8. The flexural strength of the plain specimen was found to be $18.8 \mathrm{MPa}$. The flexural strength decreased with an increased substitution ratio, and it was measured to be $12.1 \mathrm{MPa}$ at a substitution ratio of $100 \%$. However, up to $50 \%$ substitution, the flexural strength was higher than $14 \mathrm{MPa}$, which is the prescribed level for extrusion concrete panels in KS F 4735. This showed the possibility of using a mix of silica powder and WCP. Accordingly, a mix in which $50 \%$ of the silica powder was substituted with WCP was used in the panel production process to fabricate panel-type specimens that include a void section, as shown in Figure 9. The specimens were then assessed for the flexural strength by trisection loading, as shown in Figure 9. The results of measuring the strengths of the 6 specimens are shown in Figure 10. In the case of the bar-type specimen, its strength was measured to be above $16 \mathrm{MPa}$, while the strength of the panel-type specimen was slightly lower at 14.1 15.2 MPa. Nevertheless, the strengths of both types were above $14 \mathrm{MPa}$, as prescribed by KS, and based on these results, it is deemed that the desired strength may be achieved more stably by adding a fiber material that can reinforce the flexural strength.

Table 4. Mixture design.

\begin{tabular}{|c|c|c|c|c|c|c|c|c|}
\hline \multicolumn{9}{|c|}{ Unit Weight $\left(\mathrm{kg} / \mathrm{m}^{3}\right)$} \\
\hline \multirow{2}{*}{ ID } & \multicolumn{3}{|c|}{ Binder } & \multicolumn{2}{|c|}{ Fiber } & \multirow{2}{*}{\multicolumn{2}{|c|}{ WollastoniteHPMC * }} & \multirow{2}{*}{ Water } \\
\hline & Cement & Silica Powder & WCP & Sepiolite & Pulp & & & \\
\hline Plain & 604.2 & 604.2 & 0.0 & 9.1 & 22.7 & 37.8 & 8.3 & 490.9 \\
\hline $\mathrm{R} * 25$ & 595.5 & 446.6 & 148.9 & 9.0 & 22.6 & 37.6 & 8.3 & 488.5 \\
\hline $\mathrm{R} 50$ & 598.4 & 299.2 & 299.2 & 9.0 & 22.4 & 37.4 & 8.2 & 486.1 \\
\hline R75 & 595.5 & 148.9 & 446.6 & 8.9 & 22.3 & 37.2 & 8.2 & 483.9 \\
\hline R100 & 592.7 & 0.0 & 592.7 & 8.9 & 22.2 & 37.0 & 8.1 & 481.5 \\
\hline
\end{tabular}

${ }^{*}$ HPMC: Hydroxy Propyl Methyl Cellulose; * R: WCP replacement and number is replacement ratio. 


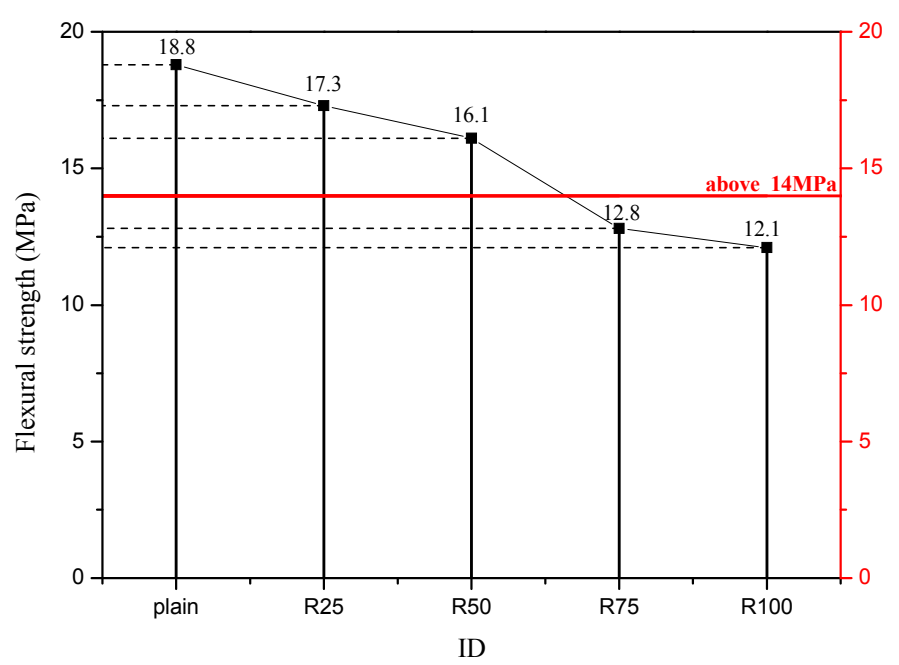

Figure 8. Flexural strength of bar type specimens.
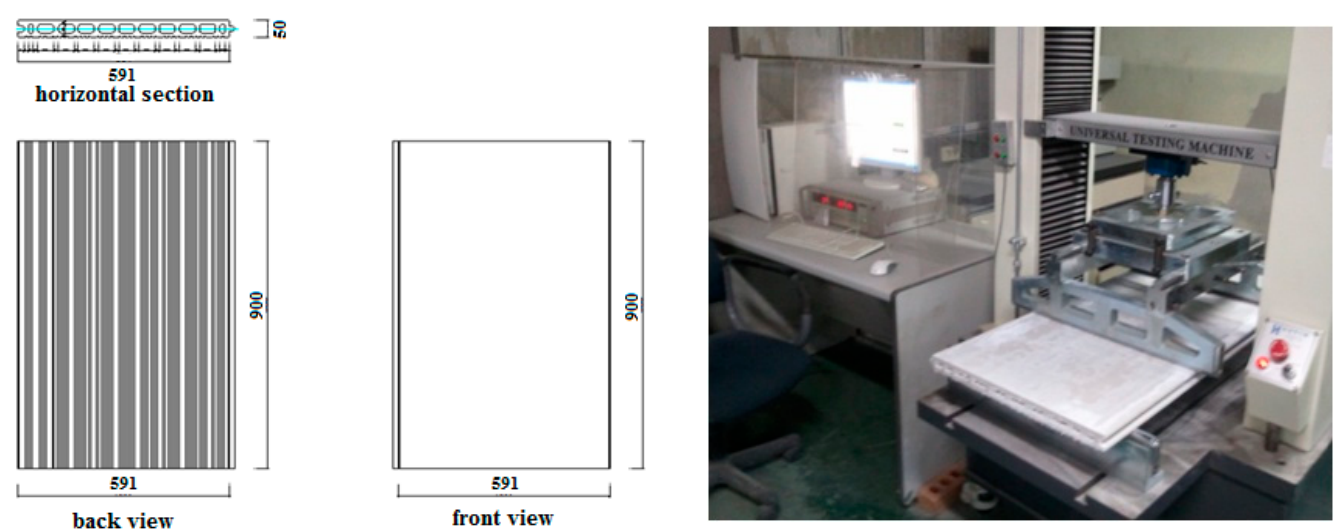

Figure 9. Shapes of panel specimens (left) and flexural strength testing set-up (right).

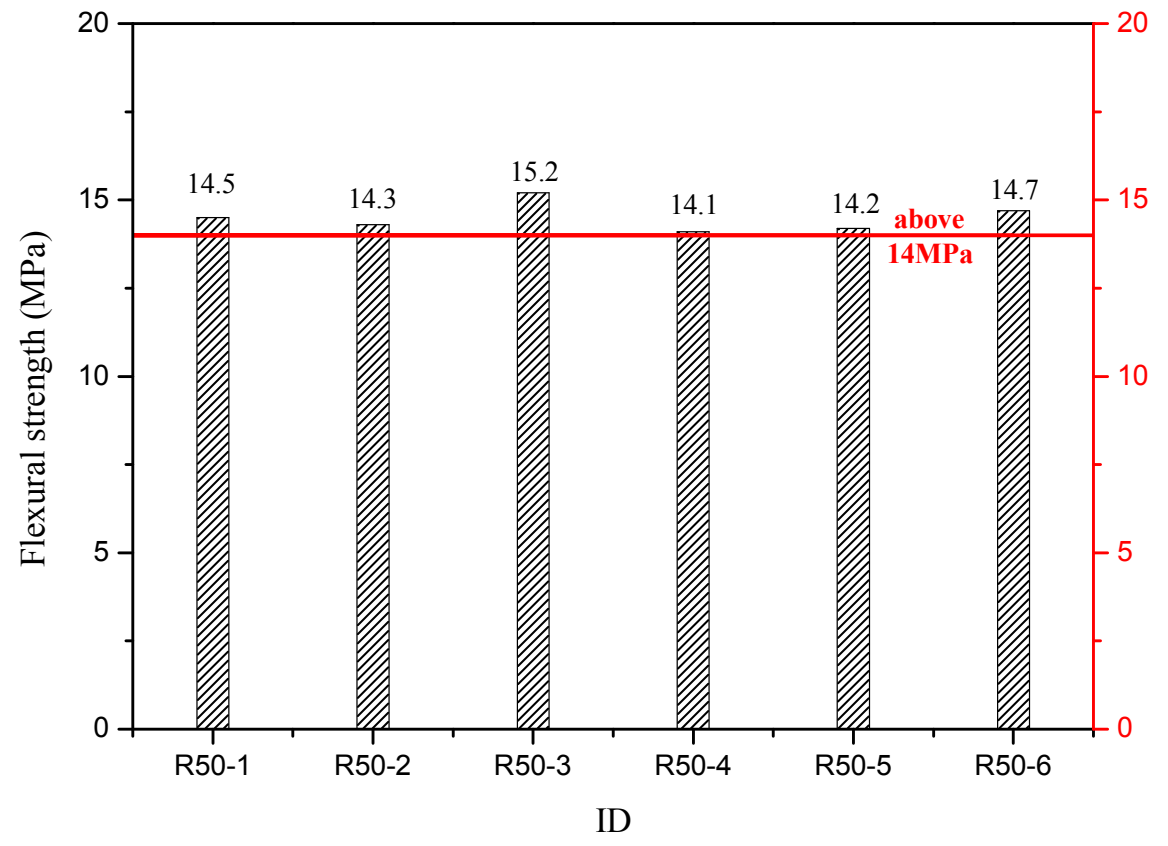

Figure 10. Flexural strength of panel type specimens. 


\subsection{Specific Gravity, Absorption Rate and Length Change}

Extrusion concrete panels are primarily used as interior and exterior materials for buildings, and thus, KS specify the requirements for not only strength, but also specific gravity, absorption rate, and rate of change in length caused by water absorption. In this experiment, the latter three factors were measured at each curing stage, and of the results are shown in Table 5. In the case of specific gravity, it was positively correlated to the silica powder-WCP substitution ratio. This is thought to be due to the fact that the specific gravity of WCP $\left(2.80 \mathrm{~g} / \mathrm{cm}^{3}\right)$ was slightly higher than that of silica powder $\left(2.66 \mathrm{~g} / \mathrm{cm}^{3}\right)$. After the curing processes, the specific gravity decreased by about $0.2 \mathrm{~g} / \mathrm{cm}^{3}$ in all of the specimens. This was due to the formation of voids in the crystal structures as a result of cement hydrates forming C-S-H systems during the steam and autoclave processes, and accordingly, the specific gravity decreased after the specimens became dry. All of the specimens satisfied the specific gravity criterion prescribed by KS, which is below 2.0.

Table 5. Specific gravity, absorption ratio and length change.

\begin{tabular}{ccccccc}
\hline \multirow{2}{*}{ Test Type } & Curing & \multicolumn{5}{c}{ Replacement Ratio (\%) } \\
\cline { 3 - 7 } & Level & Plain & $\mathbf{2 5}$ & $\mathbf{5 0}$ & $\mathbf{7 5}$ & $\mathbf{1 0 0}$ \\
\hline \multirow{2}{*}{ Specific gravity $\left(\mathrm{g} / \mathrm{cm}^{3}\right.$ ) Below 2.0} & Air-dry & 1.90 & 1.95 & 1.97 & 1.99 & 1.99 \\
& Steam & 1.72 & 1.76 & 1.81 & 1.89 & 1.92 \\
& Autoclave & 1.71 & 1.74 & 1.75 & 1.75 & 1.78 \\
\hline \multirow{2}{*}{ Absorption rate (\%) Below 18 18} & Air-dry & 6.52 & 6.65 & 7.18 & 7.15 & 9.20 \\
& Steam & 8.87 & 9.02 & 9.24 & 9.68 & 14.14 \\
& Autoclave & 12.03 & 11.97 & 12.11 & 12.31 & 14.69 \\
\hline \multirow{2}{*}{ Length change (\%) Below 0.12 } & Air-dry & 0.32 & 0.33 & 0.32 & 0.24 & 0.27 \\
& Steam & 0.19 & 0.19 & 0.17 & 0.12 & 0.13 \\
& Autoclave & 0.07 & 0.06 & 0.07 & 0.07 & 0.10 \\
\hline
\end{tabular}

KS prescribes that the absorption rate be lower than $18 \%$. The results of the absorption rate test showed that the more curing stages (air-dried curing, steam curing, and autoclave curing) and the higher the substitution ratio, the higher the absorption rate was. To be more specific, the specimen with a $100 \%$ substitution ratio that was autoclave cured, had an absorption rate of $14.69 \%$. An increase in the absorption rate caused by curing is deemed to be caused by the enlargement of voids in the crystal structures resulting from the formation of tobermorite crystals and C-S-H hydrates, as mentioned above. On the other hand, an increase in the absorption rate, caused by an increase in the substitution ratio, is deemed to result from the fact that there are more pores in the old cement paste hydrates in WCP than in silica powder. KS prescribes that the rate of change in length caused by absorption to be lower than $0.12 \%$. The results of the experiment showed that the changes caused by the substitution ratio were minor, while there were variations caused by the number of curing stages that were conducted. The rate of change in length decreased with more curing stages, and this was determined to be due to the stabilization of the hydrate structures. The specimen, which was autoclave cured, was the only one that satisfied the specification of KS. Based on the results of the three tests above, it was determined that the autoclave curing is an essential element in producing extrusion concrete panels that conformed to KS, and that the formation of tobermorite had a strong influence on product stability.

\subsection{Thermal Conductivity and Fire-Resistance}

Thermal conductivity and fire-resistance are important characteristics of extrusion concrete panels, which are used as interior and exterior construction materials. In both experiments, a plain mix with $100 \%$ silica powder and an R50 mix with a 50\% silica powder-WCP substitution ratio were used in the panel production process. In the case of the thermal conductivity experiment in Figure 11, the panels were cut into a dimension of $300 \times 300 \times 50 \mathrm{~mm}$, and HFM436 manufactured by Netzsch 
(München, Germany) was used, in reference to KS M 3808: Foamed polystyrene for thermal insulation. Figure 11 shows the equipment for measuring a thermal conductivity of an extruded panel. The results of the experiment are shown in Table 6. The plain and R50 specimens had similar thermal conductivity: the plain specimen, in which silica powder was used as an aggregate, the thermal conductivity was measured to be $0.30 \sim 0.32(\mathrm{~W} / \mathrm{m} \cdot \mathrm{K})$, whereas the specimen, in which $50 \%$ of the silica powder was replaced with $\mathrm{WCP}$, had a thermal conductivity of $0.29 \sim 0.33(\mathrm{~W} / \mathrm{m} \cdot \mathrm{K})[16]$.

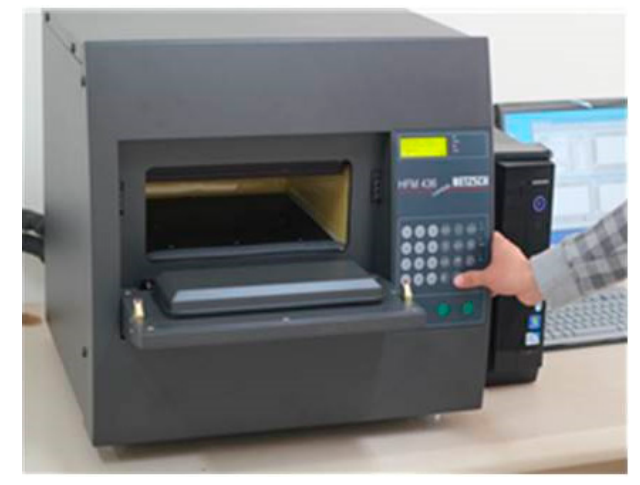

Figure 11. Thermal conductivity equipment.

Table 6. Thermal conductivity tests.

\begin{tabular}{ccccccc}
\hline Type & No. & Test Time & Mean $\mathbf{T}\left({ }^{\circ} \mathbf{C}\right)$ & Delta $\mathbf{T}\left({ }^{\circ} \mathbf{C}\right)$ & $\begin{array}{c}\text { Thermal Conductivity } \\
\mathbf{( W / m} \cdot \mathbf{K})\end{array}$ & $\begin{array}{c}\text { Termal Gradient } \\
\left(\mathbf{m}^{\mathbf{2}} \cdot \mathbf{K} / \mathbf{W}\right)\end{array}$ \\
\hline \multirow{4}{*}{ Plain } & 1 & $0: 50: 35$ & 25.67 & 20.15 & 0.302063 & 0.157386 \\
& 2 & $0: 21: 01$ & 25.93 & 20.10 & 0.302105 & 0.157365 \\
& 3 & $0: 21: 02$ & 26.05 & 20.08 & 0.302220 & 0.157304 \\
& 4 & $0: 56: 44$ & 25.73 & 20.00 & 0.324385 & 0.146319 \\
& 5 & $0: 21: 01$ & 25.96 & 19.96 & 0.322547 & 0.147152 \\
& 6 & $0: 21: 02$ & 26.07 & 19.94 & 0.321748 & 0.147518 \\
\hline \multirow{4}{*}{ R50 } & 1 & $0: 55: 06$ & 25.79 & 19.98 & 0.334488 & 0.142052 \\
& 2 & $0: 21: 02$ & 26.01 & 19.95 & 0.332706 & 0.142813 \\
& 3 & $0: 21: 02$ & 26.11 & 19.93 & 0.332077 & 0.143083 \\
& 4 & $0: 58: 17$ & 25.85 & 20.18 & 0.297308 & 0.160590 \\
& 5 & $0: 21: 02$ & 26.02 & 20.15 & 0.295605 & 0.161516 \\
& 6 & $0: 21: 02$ & 26.10 & 20.13 & 0.294910 & 0.161896 \\
\hline
\end{tabular}

In the case of extrusion concrete panels, fire-resistance is also considered important when they are to be used as an interior material. Fire-resistance performance may not be of significance in this particular study considering its purpose, but an experiment was conducted on fire-resistance in order to examine whether the use of WCP had any impact on the performance of the panels. For the fire-resistance experiment, two pieces of each specimen were assembled into a dimension of $1 \times 1 \mathrm{~m}$. The fire-resistance testing method for panels is prescribed in KS F 2257-8: Method of fire resistance test for elements of building construction-Specific requirements for non-loadbearing vertical separating elements. The fire-resistance experiment was conducted in accordance with the above standards, and accordingly, the assessment items were divided into flame and thermal interruption performances. In the case of the thermal interruption performance, the time before interrupting the non-heated surface, which is unexposed to the flames, from reaching an average temperature increase of $140{ }^{\circ} \mathrm{C}$, and the time before interrupting a particular spot from reaching the maximum temperature increase of $180^{\circ} \mathrm{C}$ are specified. On the other hand, as for the flame interruption performance, there should be no heat or red heat on the cotton pads or the flames that exist for more than $10 \mathrm{~s}$, and the crack gauge should not be penetrated [17,18].

Table 7 and Figure 12 show the results of the fire-resistance experiment performed on the plain and R50 specimens for 120 min under the standard time-heating curve condition. The initial temperature 
at the beginning of the test was $21{ }^{\circ} \mathrm{C}$ for both cases. The standards prescribe that the non-heated thermocouples do not have an average temperature exceeding $161^{\circ} \mathrm{C}$, or that the highest temperature of one of the thermocouples does not exceed $20^{\circ} \mathrm{C}$. However, the plain and R50 specimens both exceeded these limits at $33 \mathrm{~min}$ and $35 \mathrm{~min}$, respectively. Thus, they had a similar fire-resistance performance of $32 \mathrm{~min}$ and $34 \mathrm{~min}$, and it was determined that there were no significant changes in the fire-resistance performance resulting from the use of WCP. Compared to panel made of silica powder, the fire-resistance performance for WCP slightly improved. This might be the results of a reduction of voids and pore water from the calcium type hydration products.

Table 7. Fire-resistance tests during 120min.

\begin{tabular}{|c|c|c|c|c|c|}
\hline Test Items & \multicolumn{2}{|c|}{ Performance Criteria } & \multicolumn{2}{|c|}{ Test Result Plain/(R50) } & $\begin{array}{c}\text { Fire Resistance } \\
\text { Plain/(R50) }\end{array}$ \\
\hline \multirow{3}{*}{$\begin{array}{l}\text { Flame interruption } \\
\text { performance }\end{array}$} & \multicolumn{2}{|c|}{ Penetration of crack gauge } & N/A (N/A) & $120 \mathrm{~min}(120 \mathrm{~min})$ & \multirow{7}{*}{$32 \mathrm{~min}(34 \mathrm{~min})$} \\
\hline & \multicolumn{2}{|c|}{ Ignition of pads surface } & N/A (N/A) & $120 \mathrm{~min}(120 \mathrm{~min})$ & \\
\hline & \multicolumn{2}{|c|}{$\begin{array}{l}\text { Occurrence of flame } \\
\text { (10 s and over) }\end{array}$} & N/A (N/A) & $120 \mathrm{~min}(120 \mathrm{~min})$ & \\
\hline \multirow{4}{*}{$\begin{array}{l}\text { Thermal } \\
\text { interruption } \\
\text { performance }\end{array}$} & Initial Temp. & - & $\begin{array}{c}\text { Mean } 21^{\circ} \mathrm{C} \\
\left(\text { Mean } 21^{\circ} \mathrm{C}\right)\end{array}$ & - & \\
\hline & $\begin{array}{l}\text { Mean temp. } \\
\text { (non-heating } \\
\text { surface) }\end{array}$ & $161^{\circ} \mathrm{C}$ & $163^{\circ} \mathrm{C}\left(162^{\circ} \mathrm{C}\right)$ & $33 \mathrm{~min}(35 \mathrm{~min})$ & \\
\hline & $\begin{array}{c}\text { Max temp. } \\
\text { (non-heating } \\
\text { surface) }\end{array}$ & $201^{\circ} \mathrm{C}$ & $206^{\circ} \mathrm{C}\left(209^{\circ} \mathrm{C}\right)$ & $42 \min (43 \mathrm{~min})$ & \\
\hline & $\begin{array}{c}\text { Portable } \\
\text { thermocouple }\end{array}$ & - & - & - & \\
\hline
\end{tabular}

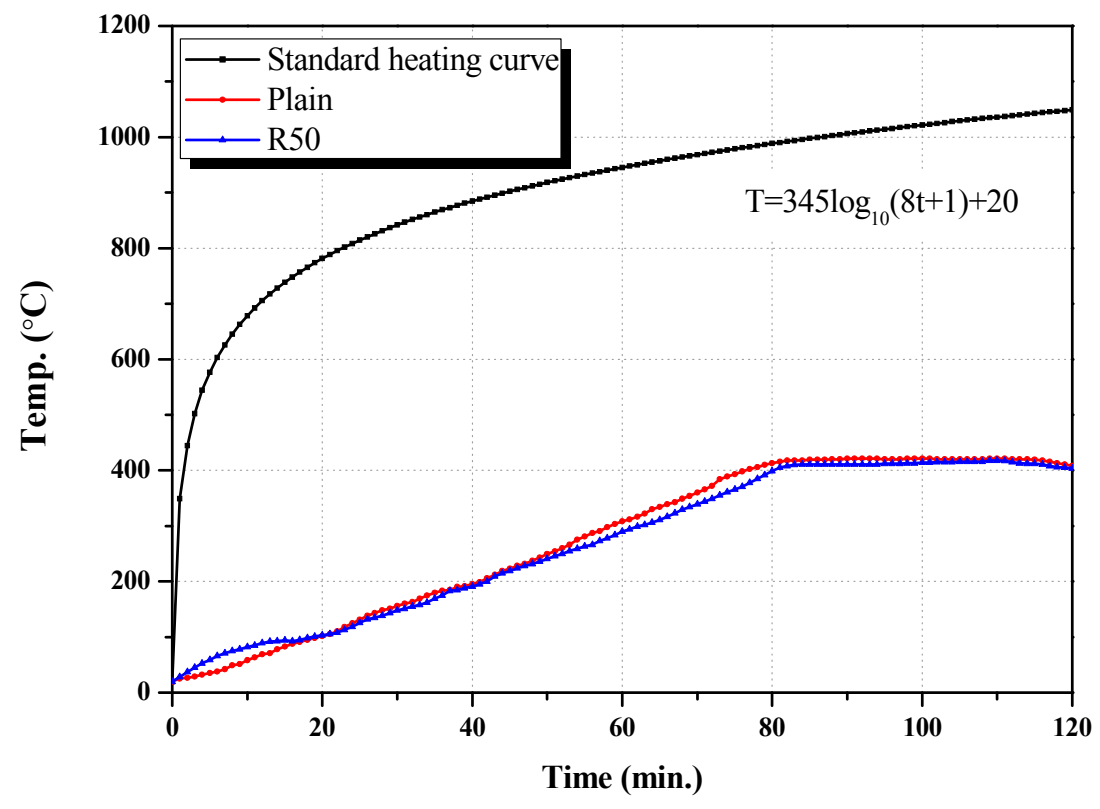

Figure 12. Time vs. temperature curves in fire-resistance tests.

\section{Conclusions}

The following conclusions were reached based on the experiments involving the use of waste concrete powder, a byproduct generated in the process of recycling waste concrete, to replace silica powder, which acts as a source of $\mathrm{SiO}_{2}$ and filler during autoclave curing, in the production of extrusion panels: 
(1) An increase in the silica powder-WCP substitution ratio results in weakened strength, but the strengths of specimens with lower than a $50 \%$ substitution ratio surpassed the prescribed strength requirement of $14 \mathrm{MPa}$, and the strength of the specimen with a $50 \%$ substitution ratio also satisfied the requirement, which confirmed the possibility of using WCP.

(2) The specimens in which WCP was used had a higher specific gravity and absorption rate when compared to the plain specimen in which only the silica powder was used, while the rate of change in length caused by water absorption was lower in the former specimens or equivalent. A review was performed in regard to the curing conditions, and the results showed that autoclave curing was essential in extrusion panel production as it not only ensured the strength of the panels, but also had an impact on density, absorption rate, and rate of change in length. The specimens containing WCP also satisfied the related standards.

(3) The results of the thermal conductivity and fire-resistance tests showed that the specimens containing WCP had equivalent or superior characteristics in comparison to the plain specimens. This is deemed to be caused by the material characteristics of WCP, such as pores and bound water [19].

(4) Based on the aforementioned experimental results, it was concluded that WCP, a byproduct from the recycling of waste concrete, is an adequate material to substitute silica powder in the production of extrusion concrete panels, which essentially do not require high purity. Based on this, the application of WCP to extrusion concrete panels and various fillers is expected to contribute to the reduction of treating byproducts, which are currently buried into the ground, and to the environmental protection efforts as it will help reduce the consumption of natural resources. Additional profits are also expected for the construction waste processing firms, as value is given to WCP, the yield of which has been increasing as a result of the production of high-quality recycled aggregates.

Acknowledgments: (1) This research was supported by a grant (code 16SCIP-C120606) from Smart Civil Infrastructure Research Program (SCIP) funded by the Ministry of Land, Infrastructure and Transport (MOLIT) of the Korean government and Korea Agency for Infrastructure Technology Advancement (KAIA); (2) This research was supported by Basic Science Research Program through the National Research Foundation of Korea (NRF) funded by the Ministry of Education (2017R1D1A1B03033898).

Author Contributions: H.S.K. and B.K. conceived and designed the experiments; H.S.K. and B.K. performed the experiments; H.S.K., B.K. and S.H.L. analyzed the data; H.S.K., B.K. and S.H.L. wrote the paper.

Conflicts of Interest: The authors declare no conflict of interest.

\section{Abbreviations}

The following abbreviations are used in this manuscript:

$\begin{array}{ll}\text { OPC } & \text { Ordinary Portland Cement } \\ \text { WCP } & \text { Waste Concrete Powder } \\ \text { VSIC } & \text { Vertical Shaft Impact Crusher } \\ \text { HPMC } & \text { Hydroxy Propyl Methyl Cellulose } \\ \mathrm{KS} & \text { Korea Standard } \\ \mathrm{CSH} & \mathrm{CaO}-\mathrm{SiO}_{2}-\mathrm{H}_{2} \mathrm{O} \\ \mathrm{C}_{5} \mathrm{~S}_{6} \mathrm{H}_{5} & 11 \AA \text { tobermorite } \\ \mathrm{C}_{5} \mathrm{~S}_{6} \mathrm{H}_{9} & 14 \AA \text { A tobermorite }\end{array}$

\section{References}

1. Kim, J.M.; Kim, K.S.; La, J.M.; Choi, D.J. Application of Waste Concrete Powder as Silica Powder of Cement Extruding Panel. J. Korea Recycl. Constr. Resour. Inst. 2011, 6, 88-94.

2. Kim, K.Y.; Kwon, S.K.; Lee, D.H.; Kim, M.H. Manufacturing Technology of Recycled Fine Aggregate by High Speed Impact and Dry Separation Method of Fine Particle. J. Korea Recycl. Constr. Resour. Inst. 2010, 5, 35-39. 
3. Kim, H.S.; Baek, D.H.; Lee, S.H. Strength Properties of Extrusion Panel Using Low Energy Curing Admixture (LA) based on Ground Granulated Blast-Furnace Slag and Electric Arc Furnace Slag. In Proceedings of the 25rd Annual Conference of Japan Society of Material Cycles and Waste Management, Hiroshima, Japan, 15 September 2014; pp. 603-604.

4. Choi, H.G.; Jung, E.H.; Kawg, E.G.; Kang, C.; Seo, J.P.; Kim, J.M. Flexural Strength Properties of Extruding Concrete Panel using Stone Powder Sludge. J. Korea Inst. Build. Constr. 2006, 6, 115-118.

5. Choi, D.J. Development of Performance Evaluation of Fire-Resistance Extruding Panel for Partition Wall between Housing Units. Ph.D. Dissertation, Kong-Ju National University, Kong-Ju, Korea, 2013.

6. Kim, J.M.; Choi, D.J. Evaluation of Sound Insulation Performance of Extruded Cement Panel with $\alpha$-hemihydrate Gypsum. J. Korea Inst. Build. Constr. 2012, 12, 575-585. [CrossRef]

7. Hara, N.; Inoue, N. Formation of Jennite from Fumed Silica. Cem. Concr. Res. 1980, 10, 677-682. [CrossRef]

8. Song, T.H.; Park, J.S.; Lee, S.H. An Experimental study on the Fire-resistant Performance of Eco-Friendly Extruding Concrete Panel. Archit. Inst. Korea 2011, 27, 123-130.

9. Taylor, H.F.W. The Chemistry of Cements; Third Printing; Academic Press Inc.: Cambridge, MA, USA, $1979 ;$ p. 173.

10. Cho, C.G.; Han, B.C.; Lee, J.H.; Kim, Y.Y. Flexural Test on Composite Deck Slab Produced with Extruded ECC Panel. J. Korea Concr. Inst. 2010, 22, 695-702. [CrossRef]

11. Kim, H.S.; Kim, H.S.; Park, S.G.; Kim, B.J.; Kwak, E.G. Optimum Abrasing Condition for Recycled Fine Aggregate Produced by Low Speed Wet Abrader Using Sulfur. J. Korea Concr. Inst. 2008, 20, 557-563.

12. Somayeh, L.; Jan, D.; Peter, R.; Radoslaw, M.; Eric, V.R.; Hans, V.D.S. Mechanical Recycling of EOL Concrete into High-grade Aggregates. J. Res. Conserv. Recycl. 2014, 87, 117-125.

13. Kim, H.S.; Lee, S.H. Strength Properties of Mortar According to Types of Binders for Reducing Curing Process of Concrete Secondary Products for Reduction $\mathrm{CO}_{2}$. J. Korea Soc. Waste Manag. 2014, 30, 824-831. [CrossRef]

14. Powers, T.C. Some Physical Aspects of the Hydration of Portland Cement. J. Res. Dev. Lab. 1965, 3, 47-56.

15. Korean Standards Association. Extrusion Concrete Panels; KS F 4735; Korean Standards Association: Seoul, Korea, 2011.

16. Korean Standards Association. Foamed Polystyrene for Thermal Insulation; KS M 3808; Korean Standards Association: Seoul, Korea, 2011.

17. Korean Standards Association. Method of Fire Resistance Test for Elements of Building Construction-General Requirements; KS F 2257-1; Korean Standards Association: Seoul, Korea, 2014.

18. Korean Standards Association. Method of Fire Resistance Test for Elements of Building Construction-Specific Requirements for Non-loadbearing Vertical Separating Elements; KS F 2257-8; Korean Standards Association: Seoul, Korea, 2014.

19. Brodersen, K.; Nilsson, K. Pores and cracks in cemented waste and concrete. Cem. Concr. Res. 1992, 22, 405-417. [CrossRef]

(C) 2017 by the authors. Licensee MDPI, Basel, Switzerland. This article is an open access article distributed under the terms and conditions of the Creative Commons Attribution (CC BY) license (http:/ / creativecommons.org/licenses/by/4.0/). 